\title{
ACERCA DE la Naturaleza de la prescripción Extintiva
}

\author{
JOSÉ ENRIQUE BUSTOS PUECHE \\ Profesor Titular de Derecho Civil \\ Universidad de Alcalá. Ëspaña
}

\section{Introducción: Algunas perplejidades.}

W 1 puede dudarse de que el tema de la naturaleza de la prescripción 1. extintiva, si no es el famoso piélago en que Dumoulin veia zozobrar al tratado de las obligaciones divisibles e indivisibles, no le anda muy lejos. A modo de indicios probatorios de ello recordemos:

1. No es fácil encontrar precepto más lapidario que el 1961 del Código Civil: "las acciones prescriben por el mero lapso del tiempo fijado por la ley". Pues bien, este precepto no dice verdad por la sencilla razón de que el mero transcurso del tiempo no determina la prescripción de acción alguna: solamente es verdad si el beneficiario de aquélla la hace valer. No deja de ser llamativo, en efecto, que el articulo citado y todos los que le siguen dentro del capitulo III del Titulo XVIII del Libro IV del Código hayan de ser leídos corrigiendo sustancialmente el sentido literal de los preceptos.

2. Es afirmación común de doctrina y jurisprudencia que el instituto es exigencia incontestable de seguridad juridica. Y sin embargo tan, al parecer, importante requisito de seguridad no puede ser apreciado de oficio por los jueces y queda al arbitrio de los particulares que pueden actualizarlo o no.

3. Servirá al menos la institución para señalar la duración de un derecho o acción: esos plazos que leemos en los aludidos artículos indicarán el comienzo y el final de la vida de los derechos o de las acciones. Pues tampoco. Y no sólo porque mediante su interrupción los plazos puedan alargarse indefinidamente, sino también porque aun dentro del plazo de duración de un derecho o acción, antes pues de su consumación, puede estimarse abusivo su ejercicio por retraso desleal. De manera que al igual que es posible ejercitar el derecho más allá del plazo establecido en la Ley, lo es ver impedido su ejercicio aun antes del agotamiento del plazo. 
4. Dentro de las Disposiciones Generales con que se abre el Titulo, el artículo 1930 asegura, después de haberse referido a la prescripcion adquisitiva, que por la prescripción extintiva se extinguen "los derechos y las acciones de cualquier clase que sean". Excesiva afirmaciōn. De nuevo la interpretación no sốlo literal sino la que ofrecería cualquier persona normal resulta errónea. Para empezar los derechos personalisimos no prescriben. Para seguir, los de familia, tampoco: algunos caducan, pero no prescriben. Nos quedamos con los derechos patrimoniales como objeto de prescripción y, sin embargo, tambièn me parece excesiva la aseveración. ¿Qué sucede con los derechos y acciones de naturaleza real? ¿Resulta de aplicación la prescripción extintiva a los derechos reales? Parece una pregunta disparatada, pero quizás no lo sea tanto. En cada tipo de derecho real el plazo para adquirirlo por usucapión es de menor duración que el de perderlo por prescripción, de modo que antes de que el sujeto titular lo haya perdido por prescripción, otro lo ha adquirido antes por usucapión, to que significa que el primero lo ha perdido sin que haya tenido lugar la aplicación de la prescripción extintiva. Suele argüirse que no necesariamente. ¿En cuántos casos prescribe un derecho sin que antes otro no lo haya adquirido? La doctrina dice que ello es posible. Acepto que algún caso de laboratorio pueda imaginarse, en que a la përdida del derecho de propiedad por una parte no corresponda el dominio de la contraparte, pero precisemos bien cuál seria entonces el estado de la cuestión. Como la prescripción, en serio, sólo juega en juicio -lo veremos más adelantees claro que o la prescripción no se aplica porque el demandado no la opone o si la esgrime -lo que hará exclusivamente si no adquirió por usucapión- entonces es poseedor de la cosa y el juicio se ceñirá a quién tiene un mejor derecho para poseer, que es el objeto de la acción publiciana ${ }^{1}$. Lo que quiero decir es que antes de que juegue la prescripción extintiva de un derecho real, otro sujeto o bien adquirió el dominio sobre él, supuesto normal, o bien al menos el cierecho de posesión porque si ni siquiera hay poseedor tampoco habrá prescripción por falta de alguien que pueda oponerla, sin cuyo requisito el instituto no se aplica.

\footnotetext{
'Sobrc el objeto de la acción publiciana, que muchos desdeñan, puede verse mi trabajo en Revista de Derecho Privado, mayo 1991.
} 
En resumidas cuentas, que de verdad unicamente prescriben o pueden prescribir los derechos de crédito.

5. Para concluir el capitulo de perplejidades, aludamos al manido tema del objeto de la prescripción. No sabemos si se extingue el derecho o la acción que lo ampara ante los Tribunales cuando el obligado no quiere satisfacerlo voluntariamente. No está mal para una institución: que ni siquiera sepamos en qué consiste. Si afirmamos que prescribe el derecho, habrá que aceptar que si el deudor, después de haber alegado la prescripción y ganado el juicio, luego paga al acreedor, estará realizando a favor de éste un negocio a título gratuito. Pero si se defiende la tesis de la acción como objeto de la prescripción, entonces habrá que convenir en que los derechos de crédito son perpetuos, y si algo hay claro en la regulación legal es su voluntad acaso manifestada con mucha torpeza- de que el tiempo ha de acabar con los derechos en algún momento.

No es asunto el planteado meramente teórico. Ya he indicado un aspecto práctico según la soluciôn que se dé al debate sobre el objeto: chay o no donación? Si la hay, habrá repercusiones fiscales, sucesorias, para los acreedores defraudados... Ademâs, de esa solución depende que se admita o no la repetición de la deuda prescrita pagada por error. O que se pueda o no oponer la excepción de compensación, lo que será posible por mucho tiempo que haya transcurrido, si el crédito subsiste. Que perviva la acción hipotecaria que protege un derecho de crédito garantizado con hipoteca, después de haberse extinguido la personal, más breve, etc.

En las siguientes páginas trataré de despejar, en la medida de mis fuerzas, algunas de las incertidumbres aludidas.

\section{El fundamento de la prescripción extintiva.}

Hay en la doctrina interés por conocer el fundamento de una institución, su razôn de ser o la finalidad que cumple en el Ordenamiento jurídico, porque se piensa que su averiguación, sin duda, ayuda a la hora de interpretar la regulación de aquélla. En el caso que nos ocupa es unánime la opiniôn de que la seguridad juridica es el fundamento y la razón de existir de la prescripción extintiva. La llamada opinión subjetiva, que veía una presunción de abandono o renuncia en el derecho prescrito puede estimarse ya superada. Pues bien, a mi juicio, quizás esta explicación del instituto pueda revisarse. 
Cuando se habla de una institución me da la impresión de que apenas se explica algo cuando se afirma que un principio general del Derecho es el fundamento de aquélla. Acontece que los principios son los fundamentos del orden juridico -ahora constitucionalizados muchos de ellos, por lo que el desdén con que algunos los han mirado ya no está justificado- $y$, por ende, subyacen a todas o a la inmensa mayoria de las instituciones, de modo que no pasa de ser una explicación muy general, aun siendo cierta. Asi, al igual que se afirma que la seguridad juridica es el fundamento de la prescripción extintiva, también se predica la misma razón de ser de la usucapion, y de la posesión, y de la apariencia juridica, y de los Registros públicos...y podiamos alargar la enumeración indefinidamente.

Sin duda, se pretende dar certeza a las relaciones juridicas con la prescripción, pero tambièn en su regulación se pretende dar al conflicto entre acreedor y deudor una solución justa, y respetar un amplio margen đe autonomia privada, que también son principios generales del Derecho. $Y$ con dificultad se hallará institución que no esté inspirada en los mismos fundamentos. Probablemente haya que despreocuparse de este punto que parece capital a la hora de estudiar las instituciones juridicas; no tanto porque no revista importancia cuanto porque se deba dar por sabido. El fundamento de las instituciones del Derecho es el del Derecho mismo y el estudio de èste es más propio de la Filosofía del Derecho que de las Ramas positivas, sin perjuicio de que, en efecto, puedan descubrirse finalidades muy concretas y especificas en determinadas figuras o institutos, en cuyo caso si que es verdaderamente útil aprehenderlas. La prohibición del pacto comisorio en las garantias reales, por ejemplo, responde a la proscripción de la ejecución privada, porque solo los Tribunales juzgan y ejecutan lo juzgado, aunque también aquella prohibición esté inspirada en los principios generales a que nos venimos refiriendo. En otras palabras, o se descubre en la institución una finalidad muy concreta y privativa de ella o se renuncia a la tarea de buscar fundamentos porque serán los generales de todo el Derecho, y como tales ayudarản poco para captar la esencia de la institución o interpretar con más acierto su regulación.

Tal ocurre, en mi opinión, con la prescripción extintiva. Lo que pretende es sencillamente resolver un conflicto entre personas de una manera razonable, justa. O sea, 10 que pretende el Derecho y todas y cada una de sus instituciones en cualquier comunidad: arreglar una controversia entre partes con criterios de justicia, para evitar la tentacion de que alguno se la tome por su mano. Si no hay más detrảs de la prescripción, 
en concreto, no hay finalidad pública, de interés general -repito, sin perjuicio del cimiento común a ésta y a todas las instituciones de los principios generales- entonces nos hallamos dentro del Derecho Privado y por ende resaltando su naturaleza privada sobre la puiblica, su naturaleza dispositiva mejor que imperativa; en fin, estamos conviniendo en que es asunto entregado a la libre disposición de los particulares, por ser privados los intereses preponderantes en juego. Como son privados, debe prevalecer la autonomia privada: nadie mejor que los mismos interesados para saber qué sea lo justo y más conveniente entre ellos.

Me parece que solamente con la explicación que acabo de ofrecer es posible entender que la prescripción extintiva no funcione automáticamente, sino que sea insoslayable la voluntad del deudor; o que el Tribunal no la pueda apreciar de oficio.

\section{Algunas notas caracteristicas de la prescripción extintiva.}

Nos preguntamos ahora por las notas caracteristicas de la institución; nos permitirán hacernos cargo mejor de su concepto y funcionamiento. Ocurre, sin embargo, que tampoco hay excesivo acuerdo sobre aquêllas. En mi opinión, éstas son sus notas más relevantes:

$1^{\text {a }}$ La prescripción no opera automáticamente sino en virtud de la voluntad del deudor. Ello significa que sólo desplegará sus efectos si se esgrime por el beneficiario de ella: sólo si el deudor, ante el ejercicio de su derecho por el acreedor, fuera del plazo fijado por la Ley, opone la prescripción de aquél, se estimará extinguido el derecho - la acción que lo ampara -ya lo veremos-, de modo que si el obligado no utiliza esta defensa que el Ordenamiento pone a su disposición, el ejercicio del derecho prescrito será perfectamente eficaz.

Hoy día puede considerarse que ésta es la opinión de la doctrina dominante. ${ }^{2}$ Sin embargo no siempre se pensó asi. Autores clásicos defendieron el carácter automático del instituto, al estimar que su

\footnotetext{
2 J. L. LACRUZBERDEJO (revisado por J. DELGADO): Elementos de Derccho Civil, L. Dykinson. Madrid, 1999, pág. 327; P. DE PABLO CONTRERAS: en la obra colectiva Curso de Derecho Civil, I. Colex, Madrid 1998, pág. 244; X. O' CALLAGHAN: Compendio de Derccho Civil, I, Edersa. Madrid, 1997, pág. 540; F, REGLERO CAMPOS: en Comentarios al Código Civil y Compilaciones Forales, Tomo XXV, vol. $2^{\circ}$, Edersa. Madrid, 1994, pág. 48. Dudosa la opinión de L. DIEZ-PICAZO: La prescripción extintiva en el Código Civil y en la jurisprudencia del Tribural Supremo. Civitas. Madrid, 2003. En la pág. 96 reconoce que se conjugan mal automatisno y no apreciación de oficio, pero en las páginas $111-112$ y 144 escribe que el derecho prescrito "renace o resucita", lo que se entiende bien si se sostiene la lesis de la extinción automática pero se compadece mal con la tesis de la voluntariedad de la prescripción.
} 
renuncia lo que hacia era "restablecer" un derecho que se habia extinguido automáticamente. ${ }^{3}$

Por lo dicho, es incompleta la relación de requisitos de aplicación de la prescripción que suele expresar la doctrina. No basta con el transcurso del plazo legal, la inexistencia de acto interruptor de aquél, y la falta de reconocimiento del derecho del acreedor por su deudor: el cuarto requisito es que se alegue por el deudor porque si no la alega será condenado a pagar. Ahora bien, si paga el crédito -nadie dice que esté hacienco una donación- en lugar de oponer la prescripción, es que aquél subsistía, es que no se habia extinguido; es que sin alegación no hay extinción. $\mathrm{Me}$ parece menos convincente la opinion ya aludida de quienes pensaron o piensan que la prescripción funciona automáticamente, que hablan de un restablecimiento o rehabilitación del derecho prescrito. Seria un fenómeno totalmente desconocido en Derecho: al menos yo no conozco otro caso igual de extinción y reaparición.

$2^{\text {a }}$. Corolario de la nota precedente es que la prescripciôn no es apreciable de oficio. Nunca se ha dudado de ello y es opinión unânime de la doctrina por lo que resulta innecesaria su cita. Convienen incluso los partidarios del automatismo. En verdad no es sencillo defender que el derecho decae ipso iure o automáticamente y negar que el juez pueda declarar esa extinción, a menos que el obligado lo quiera. Dejando esto, la necesidad de alegación para que pueda ser apreciada la prescripciôn por el juez significa que en la práctica funciona a través del juego de las excepciones en el proceso. En palabras de la STS. de 20 de noviembre de 1963 (Colec. Legisl. No 892) "la prescripción extintiva no puede acordarse de oficio, y por afectar a las pretensiones de las partes, sólo cabe oponerla por el demandado mediante excepción que se promueve". En igual sentido, las de 5 de julio de 1957 (Aranz. N ${ }^{\circ} 2554$ ) o la de 22 de enero de 1999 (Aranz. $\left.\mathrm{N}^{\circ} 631\right)^{4}$.

\footnotetext{
${ }^{3}$ Asi, DE CASTRO: Temas de Derecho Civil. Rivadeneira. Madrid, 1976 (reimpresión de la cuición de 1972), págs, 166-167; CASTÁN: en todas las ediciones de su Derecho Civil Español, Común y Foral hasta la última $14^{\text {a }}$, revisada por DE LOS MOZOS, Reus. Madrid, 1984, pág. 969; ALAS, DE BUEN, RAMOS: De la prescripción extintiva, Madrid, 1918, pág. 263. Al igual que antes decía respecto al prof. DíEZPICAZO, digo ahora respecto al prof. ALBALADEJO: La prescripción extintiva. $2^{\text {" }}$ ed. Colegio de Registradores, Madrid, 2004 : tengo dudas sobre su opinión en este punto. En la página 22 a fimla que no hay extinción automática (ijpso iure), pero en la página 304 asegura que "la renuncia a la prescripción se da ya con los efectos de ésta producicos, puesto que son autonáticos"; y seguidanenle habla de! "restablecimiento de la situación anterior".

${ }^{4}$ Para mayor detalle jurisprudencial, en la línca indicada, puede verse la monografia citada de ALBALADEJO, pág.23.
} 
Es, pues, "un medio de defensa a disposición del sujeto" Algunos autores, en este momento, se plantean si la prescripción es excepción de naturaleza procesal o sustantiva. Me parece que no puede dudarse de la naturaleza sustantiva de aquêlla. Las procesales arguyen alguna irregularidad de esta indole, que impiden el correcto establecimiento de la relación juridico-procesal ${ }^{6}$. En cambio, las materiales o sustantivas -cuya existencia niega algún sector de la doctrina procesalista, precisamente porque no dicen relación propiamente con el proceso- son medios de defensa apoyados en el Derecho sustantivo: remiten al mismo derecho subjetivo que se discute, de suerte que niegan su existencia, eficacia o subsistencia: asi, la prescripción, compensación, transacción, pago, promesa de no pedir, etc. Aunque prospere la alegación de una del primer grupo, la acción podrá ejercitarse de nuevo, si no es posible la subsanación del defecto denunciado en el mismo proceso pendiente. Pero si prospera una excepción del segundo grupo, ya no cabe volver a plantear el proceso, porque no hay derecho subjetivo que sostenga la acción judicial:

$3^{\text {a }}$ La prescripción puede operar extrajudicialmente. También es común esta afirmación en los autores que aluden a este punto concreto? Sin embargo, creo que hay que hacer alguna matización.

Las normas de Derecho Civil, a diferencia por ejemplo de las de Derecho Penal, pueden cumplirse fuera del proceso. Es más si no fuera así, la comunidad social se disolveria en el caos: resultaria enteramente imposible lograr la aplicación forzosa de las normas civiles en todos y cada uno de los casos en que estân llamadas a realizarse. La afirmación tiene visos de perogrullada, pero al parecer algunos la tienen algo olvidada: Ios que se empeñan en asegurar que el normativismo está superado porque el Derecho de verdad es el que se realiza judicialmente. Lo realmente relevante, afirman, es cómo se entiende y aplica por los Tribunales -los mâs osados dicen por el Tribunal Constitucional que, en sentido riguroso, ni es un tribunal ni ejerce jurisdicción por mucho que otra cosa afirme él y los colegas de esa disciplina- la norma. ¿Qué porcentaje de Derecho, especialmente Privado, se aplica judicialmente?...

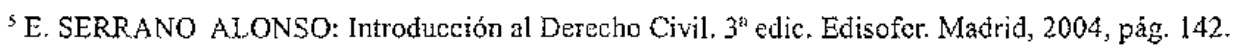

${ }^{6}$ El attículo 416 de la LEC. chumera entre ellas, como principales y más frecuentes, las siguientes: falta de capacidad procesal, cosa juzgada, litispendencia, falta de litisconsorcio necesario, inadecuación de procedimiento y defecto legal en et modo de proponer la demanda.

' Cfr. DÍEZ-PICAZO: Comentarios al Código Civis. Ministerio de Justicia. Madrid, 1991, pág. 2152; LACRUZ: op. cit. pág. 327; O' CALLAGHAN: op. cit. pág. 540. 
Entonces, no se puede mantener que lo importante son las sentencias, cuando en un $90 \%$-por decir una cifra- de los casos son los ciudadanos quienes espontáneamente cumplen las normas. Pero volvamos a lo nuestro.

En efecto, el acreedor puede acatar la prescripción objetada por su deudor, cuando extrajudicialmente le reclama el pago, y no seguir adelante con su reclamación. Pero si después volviera de su acuerdo inicial y reclamara judicialmente la deuda y el deudor no excepcionara en el momento procesal oportuno la prescripción, se dictaria sentencia condenatoria, aun en el caso de que constara en autos aquella objeción extrajudicial del deudor. De modo que si quiere liberarse de su obligacion habrả de articular la excepción dentro del juicio, aunque ya lo hubiera hecho antes fuera de él. Por lo demäs es lo que acontece con todas las defensas que exigen su utilizaciôn a través del mecanismo procesal de la excepción.

La naturaleza de remedio procesal del instituto que estudiamos asi como la conveniencia de hacer esas matizaciones anunciadas todavia destacan más a la vista del artículo 1937 del Código: "Los acreedores, y cualquier otra persona interesada en hacer valer la prescripción, podrán utilizarla a pesar de la renuncia expresa o tácita del deudor o propietario". Olvidemos al propietario porque aqui quiere decir adquirente por usucapión y no es nuestro tema. Las otras personas interesadas son los codeudores o fiadores. Para ellos vale lo mismo ya expresado respecto al deudor principal. Fijémonos en los acreedores de un deudor que ante la reclamación de otro acreedor no quiere hacer valer la prescripción que le liberaria del pago. Aquéllos se ven perjudicados porque se disminuye el patrimonio del deudor, sin que ellos participen, al menos a prorrata. ¿Cómo pueden aprovechar la prescripción que el deudor renuncia? Pues como no sea en juicio no se me ocurre otro modo. Para esos acreedores no hay posibilidad de utilización extrajudicial đe este medio de defensa de sus intereses. Si son conocedores del proceso, podrán comparecer en él y, siempre que no haya precluido el trámite, excepcionar la prescripción a fin de obtener una sentencia absolutoria del demandado, que asi no verá mermados sus bienes, para ventaja de los acreedores ${ }^{8}$. ¿Y si precluyó el trámite o vienen en conocimiento de la renuncia cuando ya se dictó sentencia condenatoria e incluso se pagó la deuda?.

\footnotetext{
${ }^{5}$ El modo concreto de articular en el juicio seguido contra el deudor esta defensa plantea no pocas dudas, pero es cuestión procesal que desbordaria los limites de este trabajo.
} 
En este caso estamos fuera del ámbito de la prescripción, que ya no puede usarse a pesar del artículo antes transcrito. Unicamente quedaria el recurso de la rescisión mediante una aplicación analógica del número 3 del artículo 1291 o, en caso de insolvencia del deudor, mediante la aplicación del 1292. Dificultad añadida será la exigencia de probar el fraude, inevitable si se aplican los artículos citados; requisito que no sería exigible si los acreedores llegan a tiempo de utilizar la excepción ${ }^{9}$.

Lo que no me convence en este punto es la explicación del artículo 1937 como una "ineficacia relativa de la renuncia", que valdria para uno -el deudor- pero no para otros -los acreedores- ${ }^{10}$ La prescripción se ha utilizado eficazmente o no, por quien puede hacerlo. Si lo primero, se ha extinguido el derecho y la obligación de pago; si lo segundo, subsiste y también la obligación de pago. No creo que la misma obligación de satisfacer el crédito del acreedor subsista para el deudor en solitario porque renunció a la prescripción y empero se haya extinguido si ese deudor no está en solitario sino acompañado por acreedores que 1legan a tiempo de utilizar la excepción. Lo que sucede es que la renuncia del deudor ha de ser eficaz y no lo es cuando perjudica a terceros porque entonces no es válida (artículo 6.2 del Código Civil) y pueden aprovecharse de la prescripción los acreedores, porque no ha habido renuncia ni de ellos ni del deudor. ${ }^{11}$

\section{El objeto đe la prescripción extintiva.}

Probablemente es ésta la cuestion que más se ha tratado en el debate doctrinal sobre la figura que estudiamos. ¿Cuâl es el objeto de la prescripción extintiva? ¿qué es lo que se extingue por la prescripción, el derecho subjetivo o la acción judicial que lo tutela cuando aquél no es satisfecho voluntariamente? Ante todo, importa determinar si el debate tiene alguna trascendencia práctica o no: si no la tuviera, raramente un debate estaria justificado en una Ciencia como el Derecho, eminentemente práctica. Pero sí la tiene.

Si como consecuencia de la prescripción objetada por el deudor se extingue el derecho, es evidente que si más tarde el deuclor se arrepiente y paga está realizando un negocio juridico distinto e independiente: en

\footnotetext{
${ }^{9}$ Así, ALAS, DE BUEN y RAMOS: op. cit. pág. 281.

${ }^{10}$ Defiende esta explicación DÍEZ-PICAZO en la monografia cilàda, pág. 112.

"ALBALADEJO alirna que el 1937 aplica fa regla general del artículo 6.2 y que esta defensa es independiente de la que putiera provenir del artículo 1111, por lo que no exige los requisitos de este precepto: op. cit. pág. 317 y 319 , con cita de otros autores en el misno sentido.
} 
concreto un negocio a título gratuito, porque los derechos no reviven; no puede ser el cumplimiento del negocio original del que nació el crédito prescrito. ${ }^{12} \mathrm{Y}$ si el pago fue involuntario, pensando por ejemplo que pagaba un crédito diferente del prescrito por su voluntad, habrá lugar a repetir el pago indebido. Además el crédito prescrito no podrá oponerse en compensación. $Y$ si lo que se extinguió por prescripción fue la acción judicial, el derecho permanece vivo, no se podrá reclamar ante los Tribunales, pero si luego hay pago, ni será una atribucion lucrativa a favor del acreedor ni se podrá repetir. Además siempre se podrâ hacer valer mediante la compensación ante la reclamación del acreedor.

Vale la pena pues aclarar, si podemos, cuál sea el objeto de la institución, aun reconociendo que en verdad no es muy frecuente que los deudores vayan por ahí renunciando a la prescripción, deseosos de pagar a sus acreedores a pesar de que podian no hacerlo.

La opinion tradicional ha sido que mediante la prescripción se extinguen derecho y acción. En rigor, decae el derecho, lo que necesariamente acarrea la extinción de la acción, que es accesorio de aquél. En apoyo de esta opinión se invocan los articulos 1930, II, y 1932, I, del Código, que hablan de extinción de derechos. Se añade, además, que no es posible distinguir ontológicamente derecho y acción ${ }^{13}$.

Diez-PICAzo se apartó de la tesis hasta entonces común y en varios trabajos de mediados de 1960 defendió que el objeto de la prescripción era la acción y no el derecho, distinguiendo entre el derecho y las facultades

\footnotetext{
"2 La caracterización del negocio a titulo gratuito no es tan simple como podfa pensarse. ¿Cuál es su esencia? Pueden darse varias respuestas: Que exista atribución de un derecho sin contrapartida; bastará con que se lucre alguna ventaja patrimonial, sin que sea preciso la adquisición de algo; es menester la correlación cntre cl empobrecimiento de tno y el enriquecimiento del otro. Para distinguir entre los supuestos citados TRABUCCHI, (Instituciones de Derecho Civil, tomo Il, pág. 474, traduc. española; Edersa, Madrid, 1967) estima que sólo en los actos de liberalidad se da esa conelación, mientras que los restantes son actos a título graturto, como el préstamo sin interés o el comodato o el depósito no retribuido, etc. La postura que se adopte servirá para la calificación del caso que nos ocupa: cl del deudor arrepentido que, no obstante haberse extinguido el crédito, paga al acreedor. En un primer momento pensé que se trataría de una donación. Cuando consulté el trabajo con el Prof. DE SOLAS me sacó de mi error, al haceme ver que no existía en ese negocio causa donandi por lo que no podia tratarse de ese negocio. En cualquier caso, y sin entrar de lteno en una cuestión que no es la principal en estos momentos, me parece quc dificilmente puede soslayarse la calificación de atribución patrimonial a favor đed acreedor a titulo gratuito, y si es un negocio gratuito tampoco será fácil eludir la tributación correspondiente, ni las demás consecuencias aparejadas en otros ámbitos: mayor exigencia de capacidad, tégimen más estricto si hay sociedad de gananciales: mayor vulnerabilidad en caso de que el deudor arrepentido tuviese otros acreedores insatisfechos, efcctos en la sucesión mortis causa, etc.

13 Vid. ALAS, DE BUEN, RAMOS: oj3. cit. pág. 102; DE CASTRO: op. cit. pág.168; CASTÁN: op. cit. pág. 848. Recientemente ha seguido el mismo criterio SERRANO ALONSO: op. cit. pág. 142.
} 
que lo integran, una de las cuales era el poder de accionar ${ }^{14}$. Realmente tampoco faltan argumentos de lege data para sostener esta opinión: después del capitulo I del Titulo XVIII, "Disposiciones generales", en el que leemos los dos artículos antes aludidos, ya no se vuelven a mencionar los derechos como objeto de prescripción sino exclusivamente las acciones, hasta el punto de que el capitulo IH, que es el dedicado a la prescripción extintiva, lleva por rúbrica "De la prescripción de las acciones". Esta tesis procesalista parece más del agrado de la doctrina moderna, con alguna excepción ${ }^{15}$. Con todo, la que parece imponerse es una versión de la tesis procesalista indicada, según la cual lo que se extingue no es propiamente la acción sino la pretensión; no la acción en sentido procesal, sino en sentido sustantivo ${ }^{16}$.

A mi juicio, el debate sigue trenzado entre la tesis sustantiva y la procesalista, según se entienda que son los derechos o las acciones lo que se extingue por el paso del tiempo y la voluntad del deudor. No entiendo la postura intermedia de la pretension, según la cual, lo que se extingue es la pretension o acción en sentido sustantivo. "El objeto de la prescripción no es el derecho ni la acción - escribe SANCHEz CALERO ${ }^{17}$ pues la prescripción consiste en la facultad concedida por la ley al sujeto pasivo para negarse a cumplir; facultad de oponer la prescripción". Al parecer, el ejercicio de esa facultad extingue la pretensión del acreedor, que por lo visto ni es derecho ni es accion. Asi se expresan igualmente los otros autores antes citados, partidarios de la tesis de la pretensiôn, que es en la que ha evolucionado la inicial de la acción de DiEz-PICAzo.

Como en otras ocasiones, estamos ante una importación alemana cuya utilidad en Derecho español me parece dudosa.

El concepto de pretension fue ideado por WINDSCHEID, evocando la actio romana, a fin de trasladar al Derecho sustantivo el concepto de derecho

\footnotetext{
${ }^{14}$ Vid. En tomo al concepto de prescripción, A.D.C. 1963/IV, pág. 969. La preseripción en el Código civil, Barcelona, 1964. DÍEZ-PICAZO en la monografía de 2003, citada, habla de "facultad de prescripción" (pág. 109) y de "abdicación por el favorecido del medio de protección establecido por el Orderamiento jurídico" (pág. 192).

${ }^{15}$ La defienden también REGLERO CAMPOS: op. cit. pág. 48; F. RODRÍGUEZMORATA: Comentarios al Código Civil y Compilaciones Forales, Tomo XXv, vol. I", Madrid, 1993, pág. 42.

${ }^{16}$ Véanse: MIQUEL GONZÁLEZ: op. cit. pág. 4595; A. CAÑIZARES LASO: La caducidad de los derechos y acciones. Civitas. Madric, 2001, pág. 23; DE PABLO CON'TRERAS: op. cit pág. 241; O'CALLAGHAN: op. cit. pág. 539. F.J. SÁNCHEZ CALERO: Curso de Derecho Civit, I. Tirant lo Blanch. Valencia, 2000, pág. 280.

"Op. cit. ibidem.
} 
subjetivo procesal del Derecho romano. Los autores receptores del concepto entienden por pretensión exactamente lo mismo -hasta donde yo sè- que por derecho de crédito, esto es, el poder de exigir de otro un hacer o una omisión, de modo que coinciden ambos conceptos. ¿Entonces...? ¿Se pueden distinguir crédito y pretensión o, como dicen, crédito y acción en sentido material? ¿Qué es eso de acción en sentido material o sustantivo, sino una de las facultades integradas en en aquél? No vale decir que pretensión sirve para designar el derecho a una determinada prestación, o sea, la satisfacción forzosa del crédito, lo que no debe confundirse con el derecho a la acción. Y no vale sencillamente porque no sé de nadie que en Derecho español -ignoro qué suceda en Derecho alemán- confunda el derecho en abstracto a accionar, a pedir a los Tribunales una resolución sobre asunto contencioso de su interés, y el derecho concreto a ejercitar la acción determinada que ampara un derecho también determinado. El primero es el derecho a la tutela judicial y se reconoce en las Constituciones; el segundo es una facultad integrada en el derecho subjetivo y se dirige a su ejercicio judicial cuando voluntariamente no se satisface por el obligado, de modo que esa facultad no corresponde a todo ciudadano como el anterior derecho, sino en concreto a uno con nombre y apellidos, al titular del crédito, vinculación que se conoce en la doctrina procesal como legitimación activa, y se regula en la Ley Procesal.

En el lenguaje ordinario sólo hablamos de acción porque, salvo que nos estemos moviendo en el terreno politico-constitucional, con ese término aludimos inequívocamente a la acción en concreto que defiende un derecho en concreto. No hay error posible. $Y$ si es asi, no sé qué cosa diferente de la facultad de exigir el cumplimiento forzoso del derecho puede designarse con el término pretensión. Y si no designa nada nuevo que no supiéramos, tampoco veo la utilidad de importar nuevos conceptos innecesarios: podremos utilizar el término, pero para nombrar esa facultad, $v$ sin pensar que estamos nombrando una realidad diferente.

En la Jurisprudencia se ha dicho que "la prescripción hace referencia tan sólo a las pretensiones que las partes pueden deducir, no a los derechos que les afectan, quedando éstos sólo paralizados mediante la excepción que se promueve" (SS. T.S. de 5 de julio de 1957, A. $\mathrm{n}^{\circ} 2554$, y de 28 de enero de 1983, A. n 393). Creo que estas Sentencias usan la palabra pretensión para oponerla a la teoría del derecho -al margen de la distinción erudita antes aludida- y por tanto como sinónima de acción. Parece pues que la tesis procesalista también tiene eco en Tribunal Supremo. 
En mi opinión, el criterio clásico parece más convincente. Escribian Alas, De Buen y Ramos "derecho y acción son una misma cosa, pero es preferible decir prescripción de acciones porque siendo acción y derecho una misma cosa en dos distintos momentos, el momento que tiene más interés para la prescripción es precisamente el momento en que el derecho se manifiesta como acción; es decir, aquél en que por no querer ser cumplido voluntariamente, se acude a los Tribunales para que impongan su cumplimiento"s.

Como la prescripción es un medio de defensa procesal, según ha quedado dicho, parece necesario afirmar, por coherencia con la aseveración precedente, que el objeto inmediato de ella es la acción procesal; si se prefiere, la pretensión, pero entendiendo que son términos sinónimos. Pero ocurre que la extinción de la acción acarrea la del derecho, de manera que el objeto mediato de la prescripción es el derecho. En suma, opuesta con éxito la excepción de prescripción, se extinguen acción y derecho.

En un derecho de crédito, no es fácil imaginat un ejercicio o uso de aquē1 que no sea la reclamación del cumplimiento por el obligado. Se exigirá el cumplimiento voluntario o forzoso, pero a la postre en eso consiste el derecho, en exigir del otro una prestación de hacer o no hacer. Si se extingue la facultad de pretender su cumplimiento judicial, se extingue como consecuencia inherente el derecho porque no puede hablarse de un derecho subjetivo cuyo cumplimiento no pueda imponerse: eso será 1o que se quiera, pero no un derecho, a cuya esencia pertenece que pueda imponerse coactivamente si el obligado se muestra renuente. ${ }^{19}$

Respecto de los derechos reales expresé, al comienzo de estas líneas, que no me resulta fácil imaginar un supuesto de prescripción extintiva puro, es decir, en que el titular haya perdido su derecho sin que otro lo haya adquirido previamente por usucapión. Sin embargo, se ha creido encontrar en esta categoria de derechos un argumento a favor de la tesis procesalista, aduciendo que como en el derecho real se integran varias facultades, puede perderse por prescripción la acción amparadora de una de ellas y empero subsistir el derecho: independencia entre acción y derecho. A mî, en cambio, me parece que la inescindible vinculación entre ambas realidades juridicas todavia resalta más en los derechos reales: si el que ejercita la acción negatoria de servidumbre, por poner

\footnotetext{
18 Op. cit. pág. 102

19 Incluso la explicación ofrecida para casos semejantes de la llamada obligación natural -hoy poco aceptada, entre otras cosas porque es esos casos siempre caben otras explicaciones más técnicas- es un reconocimiento de que tin derecho no susceptible de cumplimiento forzoso sale del mundo de lo jurídico.
} 
un ejemplo, ha dado lugar a que otro haya adquirido ese derecho real limitado por usucapión, o sencillamente la ha dejado prescribir aceptando esta posibilidad a efectos dialécticos- , y el demandado opone la prescripción, es claro que no por ello el actor habrá perdido su derecho de dominio, pero no es menos claro que éste ha quedado disminuido: ha habido una consecuencia sustantiva, no sólo procesal. Ha perdido para siempre una parte de las utilidades o usos de la cosa, precisamente aquélla sobre la que ha adquirido un derecho limitado el otro. No hay pérdida solamente de una facultad de exigencia ante los Tribunales: hay decadencia del derecho, al menos de una parte de él.

Siguese de lo anterior que si el deudor opuso en juicio la excepción de prescripción y fue estimada en la sentencia:

1. El acreedor $\mathrm{o}$, en general, el demandante pierde la acción y el derecho.

2. Si el deudor paga voluntariamente después de sentencia, hace atribución gratuita a favor del acreedor de la suma entregada, con las consecuencias posibles que indicamos.

3. Si paga por error en el supuesto anterior, puede repetir el pago ex artículo 1895.

4. Si paga por error una deuda no reclamada en juicio y respecto de la que habria podido alegar con éxito la prescripción, nada puede hacer porque el crédito del acreedor no prescribe sólo por el paso del tiempo, sino que es menester que se excepcione en juicio la prescripción. Por tanto en el caso, está pagando una deuda viva. ${ }^{20}$

5. Si el crédito de un acreedor está vivo-y lo estará aunque haya pasado el plazo de la prescripción, si el deudor no la ha hecho valer en juicio, podrá servir para compensar el crédito que se le reclame. En cambio, si se hubiera extinguido el crédito porque cuando ese acreedor pretendió ejercitarlo, el obligado opuso con éxito la excepción, ya no podrá hacerlo valer posteriormente frente al entonces deudordemandado, ahora convertido en acreedor-demandante: ya no cabe la compensación porque ese crédito se extinguio.

${ }^{20}$ En contra ALAS..., pág. 273; estiman que también puede repetirse el pago ex articulo 1895. 


\section{BIBLIOGRATIIA}

- ALAS, L., DE BUEN, D., RAMOS, E.: De la prescripción extintiva. Mađrid, 1918.

- ALBALADEJO GARCIA, Manuel: La prescripción extintiva, $2^{\mathrm{a}}$ edic. Colegio de Registradores. Madrid, 2004.

- CAÑIZARES LASO, Ana: La caducidad de los derechos y acciones. Civitas. Madrid, 2001.

- CASTÁN TOBEÑAS, José: Derecho Civil Español, Común y Foral. $14^{\mathrm{a}}$ edic. revisada por José Luis de LOS MOZOS. Reus. Madrid, 1984.

- DE CASTRO Y BRAVO, Federico: Temas de Derecho Civil. Rivadeneyra. Madrid, 1976, reimp. de la edic. de 1972.

- DE PABLO CONTRERAS, Pedro: Curso de Derecho Civil, vol. I (obra colectiva). Colex. Madirid, 1998.

- DIEZ-PICAZO, Luis: La prescripción extintiva en el Código Civil y en la Jurisprudencia del Tribunal Supremo. Civitas. Madrid, 2003.

- LACRUZ BERDEJO, José Luis: Elementos de Derecho Civil, I. (edición revisada por Jesús Delgado). Dykinson. Madrid 1999.

- LASARTE ALVAREZ, Carlos: Principios de Derecho Civil, Tomo I, $5^{2}$ edic. Trivium. Madrid, 1996.

- MIQUEL GONZÁLEZ, José Maria: Comentario a la Sentencia del Tribunal Supremo de 29 de abril de 1987 , en CCJC., $n^{\circ} 14$.

- O'CAllaghan MuNoz, Javier: Compendio de Derecho Civil, tomo I. Edersa.. Madrid, 1.997.

- PUIG BRUTAU, José: Caducidad y prescripción extintiva. Bosch. Barcelona, 1986.

- REGLERo CAMPOS, Fernando: En Comentarios al Código Civil y Compilaciones Forales (dirigidos por Albaladejo y Diaz Alabart), Tomo XXV, vol. 20. Edersa. Madrid, 1994.

- RODRIGUEZ MORATA, Federico: En Comentarios al Código Civil y Compilaciones Forales (dirigidos por Albaladejo y Diaz Alabart), Tomo XXV, vol. 1०. Edersa. Madrid, 1993.

- SERRANO ALONSO, Eduardo: Introducción al Derecho Civil, $3^{a}$ edic. Edisofer. Madrid, 2004.

- TRABUCCHI, A. : Instituciones de Derecho Civil. Tomo II. Traducción española por L. Martinez Calcerrada. Edit. Edersa. Madrid, 1967. 